\title{
Current management of sinonasal undifferentiated carcinoma*
}

\author{
Fernando López', Vanessa Suárez', Blanca Vivanco², Carlos Suárez', \\ José L. Llorente' \\ ' Department of Otorhinolaryngology, Instituto Universitario de Oncología del Principado de Asturias, Hospital Universitario \\ Central de Asturias, Oviedo, Asturias, Spain \\ ${ }^{2}$ Department of Pathology, Hospital Universitario Central de Asturias, Oviedo, Asturias, Spain
}

Rhinology 53: 212-220, 2015

DOl:10.4193/Rhino14.054

*Received for publication:

February 23, 2014

Accepted: October 9, 2014

\begin{abstract}
Background: The management of sinonasal undifferentiated carcinoma (SNUC) remains unclear. Low incidence and poor outcomes make treatment standardization difficult. The objective of this study was to review the used treatment and our outcomes.

Methods: From 2001 to 2013, 17 cases of SNUC were treated at our department. Charts were reviewed for standard demographic, tumour size and extension, histological features, treatment strategies, surgical approach, adjuvant therapies, outcomes and complications.
\end{abstract}

Results: All patients presented with extensive local disease and 2 patients also had neck metastases. All patients were treated using a multimodality approach: 10 patients underwent surgery and postoperative chemoradiation, 1 patient was treated with surgery and adjuvant radiotherapy, 3 patients were treated with neoadjuvant chemotherapy, surgery and postoperative chemoradiation and the remaining 3 patients were treated with chemoradiotherapy. After median follow-up of 39 months 6 patients developed recurrences. The 3-year local control rate was $76 \%$ and the 5 -year rate of overall survival was $58 \%$.

Conclusions: Management and outcomes of SNUC have improved due to advances in surgery and radiotherapy. Gross tumour resection followed by postoperative radiotherapy should be the standard of care in patients with SNUC. High-precision high-dose radiotherapy should be implemented to try to improve the outcomes.

Key words: sinonasal undifferentiated carcinoma, multimodality approach, surgery, radiotherapy, head and neck carcinomas

\section{Introduction}

The World Health Organization defined SNUC as a highly aggressive and clinicopathologically distinct carcinoma of uncertain histogenesis that typically presents with locally extensive disease. It is composed of pleomorphic tumour cells with frequent necrosis, and should be differentiated from lymphoepithelial carcinoma and olfactory neuroblastoma ${ }^{(1)}$.

Despite that its origin remains unclear, there is increasing evidence that SNUC is a surface (Schneiderian) epithelial-derived malignancy, with or without concurrent neuroendocrine differentiation ${ }^{(2)}$. Differential diagnosis is wide because a range of similar lesions with an undifferentiated or poorly differentiated morphology may occur at this site. However, histology, immunohistochemistry or molecular biology is becoming increasingly important for choosing an appropriate treatment strategy ${ }^{(3)}$.

SNUC presents as a rapidly enlarging tumour with initially vague symptoms that are of relatively short duration. SNUC tends to be locally advanced upon presentation, and orbital, dural, or intracranial invasion are frequent. SNUC has the ability to spread regionally (30\%) and with distant metastasis. SNUC is reputed to be refractory to even the most radical therapy and to carry a poor prognosis, particularly when the tumour transgresses the skull base. 
Since its initial description in 1986, a number of case studies an small case series, with numbers ranging from 10 to 20 patients, have been reported in the literature examining outcomes in this disease, and treatment decisions are guided by these published small series. Only 167 cases have been reported in a recent meta-analysis ${ }^{(5)}$. Comparisons of outcomes of different studies have also been limited by the heterogeneous disease patterns and varying treatment regimens used.

Early reports on radiation or surgical resection alone have generally yielded poor results ${ }^{\left({ }^{6}\right.}$. A combination of radical surger chemotherapy and radiotherapy (RT) appears to provide the best chance of survil but there is sill no consensus about which modalites tor best sequence ${ }^{3}$. Nevertheles given the aggressive nature of this disease and the poor specificity in symptom presentation, the prognosis is poor, the recurrence is frequent and overall mortality is high ${ }^{(4)}$. Examination of data across studies looking at treatment modalities may yield important trends that will help guide modern decision making in such a rare and aggressive disease.

The aim of the current study is to present the experience in the management of this tumour at our tertiary care academic teaching hospital. Moreover, we analyse the relevant previously published experience from the initial description in 1986 of this tumour.

\section{Materials and Methods}

Chart review

The surgical medical charts of the Otorhinolaryngology Department of our hospital, from 2001 to January 2013, were reviewed to collect data regarding the clinical data of patients diagnosed with SNUC. The methodology was a retrospective, non-random with SNUC. The methodology was a retrospective, non-random
zed chart review. We identified 17 patients diagnosed of SNUC zed chart review. We identified 17 patients diagnosed of SNUC
(Figure 1). No patients with this diagnosis were initially treated (Figure 1). No patients with this diagnosis were initially treated with palliative care during the study time period. All patients
gave their signed informed consent, and the study had receive prior approval from the ethics committee of our institution.

Data collection was based on a review of the patients' medical histories, recorded data on age, tumour size, location, presenting symptoms, treatment modalities (surgical procedures, chemotherapy and RT), pathological findings, treatment complications, recurrence and status at last follow-up visit. Extent of the tumour was determined by evaluation of patient's paranas computed tomography (CT) and/or and magnetic resonance imaging (MRI). The data describe the extent of disease through surgical description, radiography International Union Against ging, and Kadish staging. CT scan showed erosion of the skull base and MRI scans were useful to demonstrate the intracranial and intraorbital extension. The pathology on all patients was reviewed at our institution to confirm the diagnosis of SNUC, according Franchi et al. (3) criteria. Based on the joint re commendations of multidisciplinary head and neck conference, patients were selected for treatment with surgery followed by chemoradiotherapy, induction chemotherapy followed by surgery and chemoradiotherapy, or definitive chemoradiotherapy. All patients were treated with curative intent and the goal of surgery was complete resection of tumour with negative margins, with as low morbidity as possible. Craniofacial resection was performed in all cases. Orbital exenteration was not an elective procedure but mandatory in patients with tumour invasion beyond the periorbital tissue. Criteria for unresectability were xtensive intradurat spreadi Cinvaion of the optic pathway, Invextensive intradura sprear The for The follow-up consisted of periodic visits to our Clinic. A CT and or MRI were performed annually in all patients for the first 5 years of follow-up. Duration of control was calculated from the date of finishing the last treatment modality.

Statistical Analysis

Fisher's exact test was used for comparison. Survival curves were calculated by the Kaplan-Meier method and the comparison

between subgroups was performed by Log Rank test. A P value

of $<0.05$ was considered statistically significant. All calculations were performed using SPSS 19.0 for Windows.

Results

Clinic characteristics

The patients' characteristics are shown in Table 1. The tumour

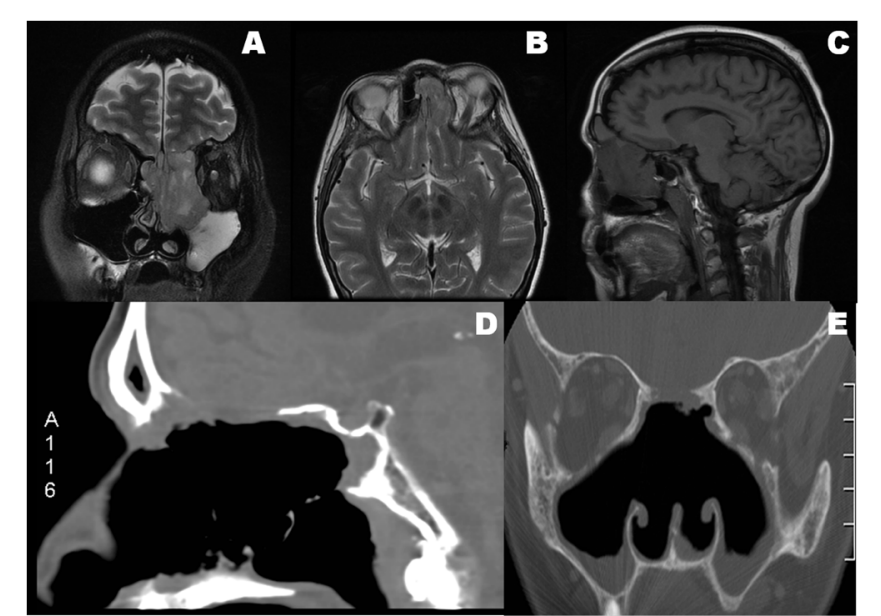

Figure 1. Example of SNUC. Coronal (A), axial (B) and sagittal (C) preoperative MR images showing a SNUC that entirely filled the left nasal cavity and etmoid sinuses. The lamina papyracea seemed to be affected by the Umour. There are sharp interfaces between the mass and the anderior esults of a total endoscopic resection of a SNUC
Table 1. Patient and tumour characteristics.

No. of patients $(\%$

\begin{tabular}{|c|c|}
\hline \multirow{2}{*}{\multicolumn{2}{|c|}{ Gender }} \\
\hline & \\
\hline Male & $9(53)$ \\
\hline Female & $8(47)$ \\
\hline \multicolumn{2}{|l|}{ Age (years) } \\
\hline Range & $38-73$ \\
\hline Median & 53 \\
\hline \multicolumn{2}{|l|}{ Follow-up (months) } \\
\hline Range & $6-96$ \\
\hline Average & 36 \\
\hline Median & 48 \\
\hline \multicolumn{2}{|l|}{ Symptoms } \\
\hline Nasal obstruction & $14(82)$ \\
\hline Orbital symptoms & $4(24)$ \\
\hline Epistaxis & $5(29)$ \\
\hline Headache & $2(12)$ \\
\hline Facial pain & 1(6) \\
\hline \multicolumn{2}{|l|}{ Tumour stage (UICC) (1) } \\
\hline Тз & $1(6)$ \\
\hline T4а & $4(23)$ \\
\hline T4b & $12(71)$ \\
\hline \multicolumn{2}{|l|}{ Kadish stage ${ }^{(2)}$} \\
\hline в & $1(6)$ \\
\hline c & $16(94)$ \\
\hline \multicolumn{2}{|l|}{ Nodal stage } \\
\hline No & $15(88)$ \\
\hline $\mathrm{N}+$ & $2(12)$ \\
\hline \multicolumn{2}{|l|}{ Site } \\
\hline Ethmoid sinus & $17(100)$ \\
\hline \multicolumn{2}{|l|}{ Intracranial invasion } \\
\hline No & $4(23)$ \\
\hline Yes (dural invasion without brain invasion) & $10(59)$ \\
\hline Cavernous sinus involvement & $3(18)$ \\
\hline Brain invasion & $3(18)$ \\
\hline \multicolumn{2}{|l|}{ Orbit invasion } \\
\hline No & $13(76)$ \\
\hline Periorbital invasion & $2(12)$ \\
\hline Orbit invasion & $2(12)$ \\
\hline
\end{tabular}

epicenter was in the ethmoid sinus in all cases. All of the patients except 1 had T4 stage by UICC criteria and only 2 patients $(12 \%$ were seen with clinically positive regional lymph nodes at presentation. Four patients were T4a (23\%) and 12 were T4b (71\%). Using the Kadish system for staging 160 o 17 Westage Using 17 was sage B. All of fartients excep 1 exhbied of 17 was stage B. All of pationts except 1 exhibited invasion of the orbit or the skull base at presentation. No patient was seen with haematogenous dissemination.

Histopathology

Prior to definitive treatment, a biopsy specimen under nasal endoscope was obtained in all patients. Histopathology showed nests, sheets or ribbons of undiffentioned small to medium sized cells without vidence of squmous or glad to medif

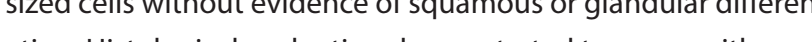
ation. Histological evaluation demonstrated tumours with areas of bone infiltration and it showed distinct features such as high mitotic activity with areas of necrosis, large, and darkly stained nuclei with prominent nucleoli and vascular invasion. Immunohistochemistry was positive for epithelial markers (cytokeratins 7 and 8 and epithelial membrane antigen (EMA)). Epstein-Barr virus (EBV) and 5100 staining were negative. Variable and low reactivity was seen in some isolated cells with neuronspecific enolase (NSE), chromogranin, and synaptophysin.

Treatmen

The summary of the treatment modalities used are shown in Table 2. The preferred treatment was craniofacial resection followed by postoperative chemoradiotherapy ( $82 \%$ of patients). We maintained a relatively aggressive posture toward surgical resection. However, in 3 patients the tumour was initially deemed unresectable because of its large size and its extensive orbitand intradua invovenent, so these parint recived ivductionche motherapy; then they underwent craniofacial resection followed by postoperative chemoradiotherapy. One patient who underwent craniofacial resection declined postoperative chemotherapy and was thus treated with postoperative RT alone. The 5 last patients were operated on by endoscopic craniofacial resection as previously reported ( ${ }^{(7)}$. Orbital exenteration was combined with craniofacial resection in 5 patients. All patients who underwent resection had all gross 5 mour removed Intraperative frozen section was used to achieve tumour-free margins. Finally, definitive concurrent chemoradiotherapy was used to treat $3 \mathrm{pa}$

Table 1.

'Sobin LH, Compton CC. TNM seventh edition: what's new, what's changed: communication from the International Union Against Cancer and the American Joint Committee on Cancer. Cancer 2010:116:5336-

h S, Goodman M, Wang CC: Olfactory neuroblastoma. A clinical analysis of 17 cases. Cancer 1976;37:1571-1576. 


\begin{tabular}{lc} 
& No. of patients $(\%)$ \\
\hline Type of treatment & $3(18)$ \\
Primary CRT & $3(18)$ \\
Induction CT, surgery and PORT & $1(6)$ \\
Surgery and PORT & $10(58)$ \\
Surgery and POCRT & \\
Radiation dose (Gy) & $64-72$ \\
\hline Range & 62.5 \\
$\quad$ Median & \\
Technique radiotherapy & $14(82)$ \\
3DCRT & $3(18)$ \\
\hline IMRT &
\end{tabular}

CRT: chemo-radiotherapy; CT: chemotherapy; PORT: postoperative radiotherapy; POCRT: postoperative chemo-radiotherapy; 3DCRT: threedimensional conformal RT: IMRT: intensity-modulated radiotherapy

tients $(18 \%)$, as primary treatment. All the patients who received chemotherapy received intravenous cisplatin-based chemothe rapy, according to the local protocol.

As describe above, all patients in our series received RT. Fourteen patients $(82 \%)$ were treated with 3-dimensional conformal RT (3DCRT), and intensity-modulated radiotherapy (IMRT) was used to treat the remaining 3 patients (18\%) RT given at given at a total dose of 64-72 Gy in 2-Gy fractions daily. There were no breaks in treatment due to acute radiation toxicities.

According to the local protocol for the treatment of paranasal sinus cancers, bilateral elective nodal irradiation (ENI) was advocated in high-risk node-negative patients with involvemen of the skin of the cheek, infratemporal fossa, pterygoid region, nasopharynx or cribriform plate Of 15 patients with a clinically negative neck, 10 patients received ENI and 5 patients did not receive elective treatment. The remaining patients with clinically positive nodes received a modified radical neck dissection and $\mathrm{RT}$ to the regional disease.

Outcomes

Disease control

Six patients (35\%) developed recurrences an average of 10 months after presentation or treatment (range 3 to 24 months) (Table 3). Of these patients, the 3 patients treated with neoadjuvant chemotherapy along with surgery and postoperative chemoradiation, had a local recurrence (patients 1,3 and 6).
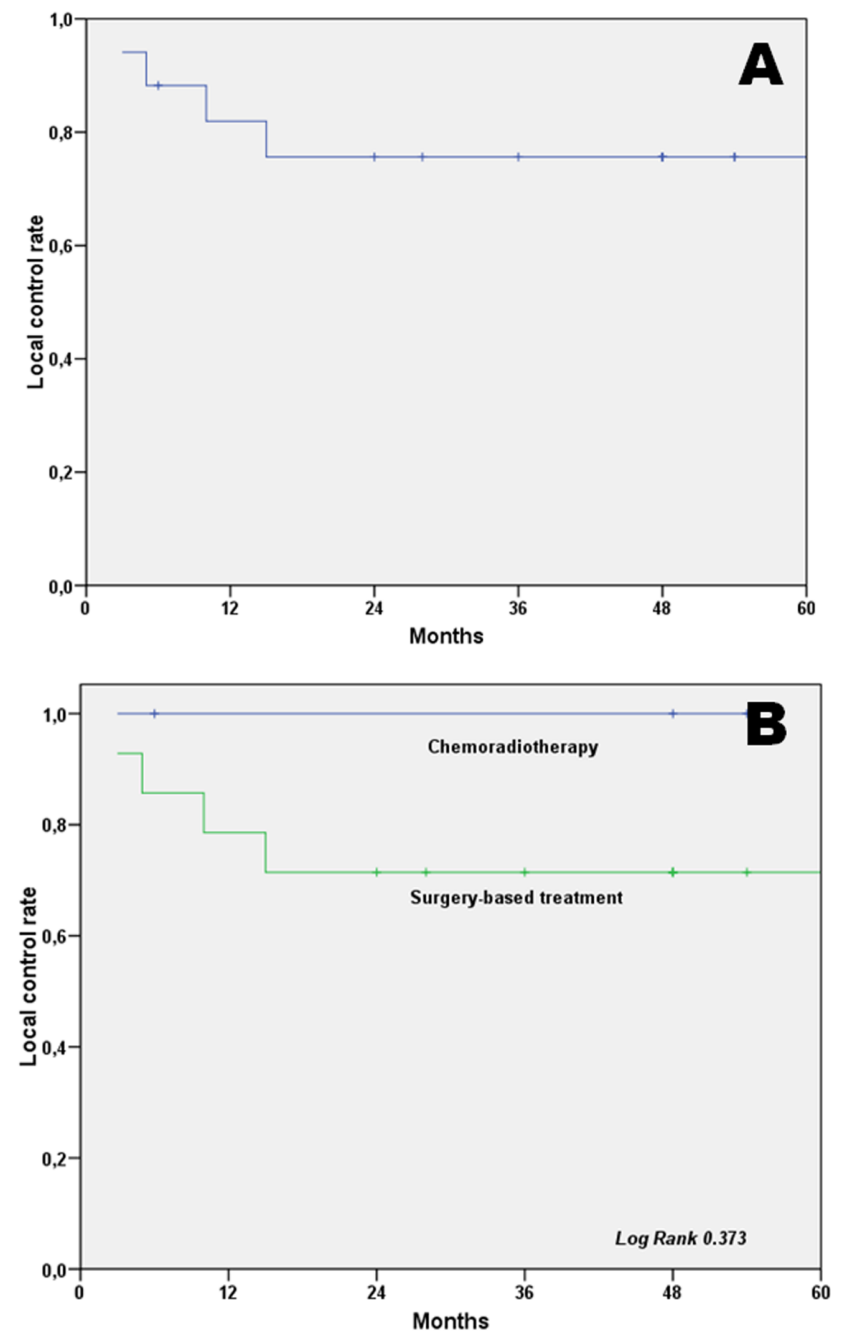

Figure 2. (A) Overall local control rate and (B) as a function of the radical surgical resection (Kaplan-Meier analysis).

Moreover, 2 of them developed a regional recurrence. All 3 patients were then treated with palliative care and died of their disease. The other 3 patients (patients 2, 4 and 5) had been treated primarily with surgery and postoperative chemoradiation. One patient showed distant metastases at the spine and another developed brain metastases. The former paine was teat dithent was treated win chemotherapy (patient 4) and the latter with surgery and RT (patient 5), and both patients eventually died of their disease. Finally, one patient (patient 2) developed recurre disease in the nasal bones and cervical lymph nodes as well as developing metastases in the spine and the liver. This patient was treated with modified radical neck dissection, chemotherapy and volumetric-modulated arc therapy (VMAT) and was alive without disease at the most recent follow-up.

Two of the 5 patients (40\%) who underwent a craniofacial endoscopic approach developed a recurrence. One patient presented distant metastases (patient 4 ) and other developed local recur-

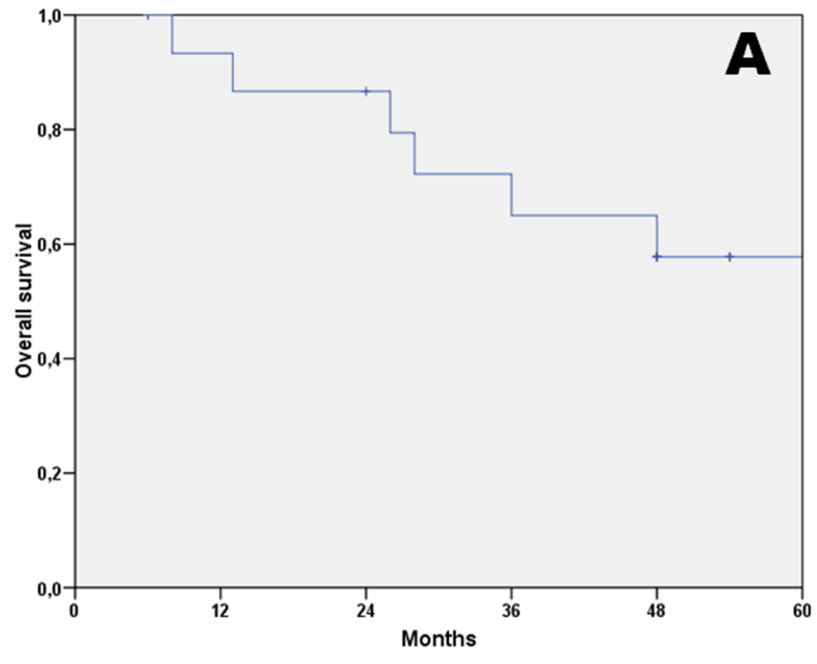

$\mathbf{A}$

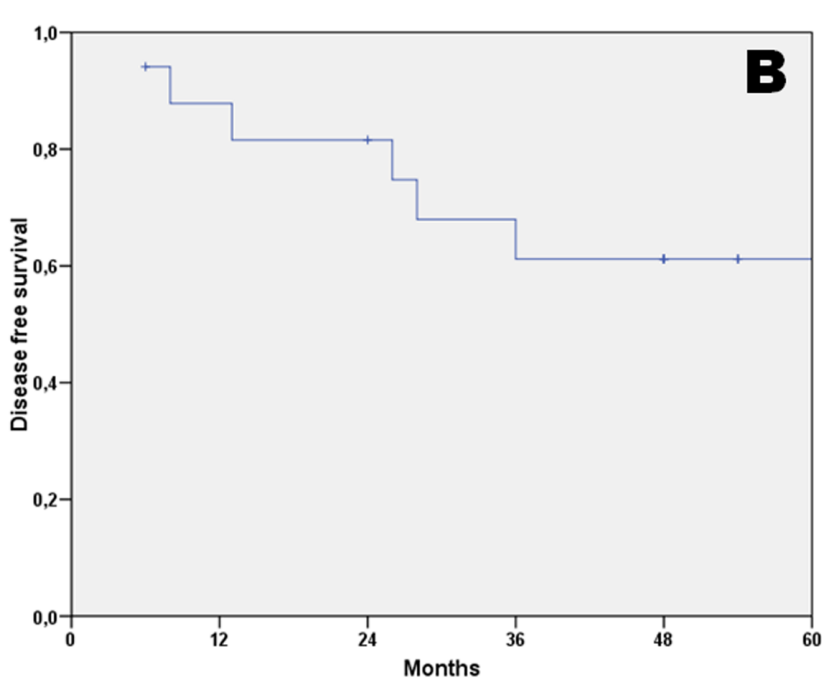

Figure 3. (A) Overall survival and (B) disease-specific survival for patients with SNUC (Kaplan-Meier analysis).

rence (patient 3). The latter patient presented initially a very advanced tumour involving the brain. Both patients finally died The 3-year local control rate was 76\% (Figure 2). The local control rates according to treatment groups were: surgery-based treatment alone, 10 of 14 (71\%); chemoradiotherapy, 3 of 3 (100\%); and absolute local control, 13 of 17 (76\%). Both in the univariate and multivariate analysis, the presence of dural or orbital invasion, and the use of surgery-based treatment versus chemoradiotherapy, were not correlated with poor local control. However, 3 of 4 patients developed local recurrence had dural invasion but did not have brain invasion.

Of the 15 patients with a clinically negative neck, the regional control rate was 10 of 10 patients $(100 \%)$ who received ENI

versus 3 of 5 patients $(60 \%)$ who did not receive elective ne irradiation. One of the patients with recurence in a linically negative neck died with regional disease alone (patient 1); one patient died with disease in both the neck and primary site (patient 6); the third patient with loco-regional recurrence underwent salvage neck dissection and is alive and disease free (patient 2). None of the patients with a clinically positive neck had recurrence in the neck. The 3-year locoregional control rate was $70 \%$. The locoregional control rates according to treatment groups were: surgery-based treatment alone, 9 of 14 (64\%); chemoradiotherapy, 3 of 3 (100\%); and absolute regional control, 12 of $17(70 \%)$.

The 3-year distant metastasis-free survival rate was $78 \%$. Three patients $(18 \%)$ with a T4b-stage tumour developed hematogenous metastases. After treatment describe above (Table 3), 2 patients died and one patient is alive without disease.

Survival rates (Figure 3 )

The median follow-up period was 39 months (range, 6 to 96 months). The 5-year overall survival (OS) was $58 \%$ and the 5 -year disease free survival (DFS) was $61 \%$. The 5 -year disease-specific survival (DSS) was $65 \%$. At their most recent follow-up, 10 patients (59\%) are alive and disease-free, 2 patients $(12 \%)$ died due to intercurrent disease without evidence of recurrence, $5(29 \%)$ patients died with cancer.

OS, DFS and DSS were also stratified by treatment type: surgery based treatment vs. chemoradiotherapy. Comparison using log-rank test demonstrated no statistical differences between treatment types. Nevertheless, there was a trend toward improved figures with primary chemoradiation.

\section{Complications}

One of 17 patients (6\%) developed severe treatment-related complications. This patient who underwent craniofacial resection and postoperative chemoradiotherapy developed multiple brain abscesses and was treated successfully; afterwards the mentioned patient died due to intracranial progression.

\section{Discussion}

Several malignant tumours occurring in the sinonasal tract may present with an undifferentiated morphology. These lesions pose significant diagnostic challenges for the surgical pathologist, especially in limited biopsy material, but their correct classification is becoming increasingly important for an appropriate stice treatment strategy. Advances in immunohistochemistry and molecular biology, as well as with previous progress in electron microscopy, have allowed to establish diagnostic criteria and classify poorly differentiated sinonasal tumours. Likewise in ou samples, immunohistochemically, SNUC is positive for epithelia markers, such as simple epithelia CK (including, CK7, CK8 and CK19) and EMA. Variable reactivity can be seen with neuronspecific enolase (NSE), p53, chromogranin, and synaptophysin ${ }^{(3,8)}$. Vimentin, muscle markers (actins, desmins, myoglobin), hematolymphoyd markers (leucocyte common antigen, B and T- cell markers), melanocytic cell markers (melan A, HMB-45) and sar- 
Table 3. Recurrence, treatment and outcomes.

\begin{tabular}{|cccccccc|}
\hline Patients & TNM & $\begin{array}{c}\text { Primary } \\
\text { treatment }\end{array}$ & Location of recurrence & $\begin{array}{c}\text { Time to recur- } \\
\text { rence (months) }\end{array}$ & Treatment & Current status & $\begin{array}{c}\text { Survival } \\
\text { (months) }\end{array}$ \\
\hline 1 & T4b & CT-S-POCRT & Regional & 10 & Palliative & D & 13 \\
\hline 2 & T4b & S-POCRT & $\begin{array}{c}\text { Loco-regional-distant } \\
\text { metastases }\end{array}$ & 3 & CRT & AWD & 6 \\
\hline 3 & T4b & CT-S-POCRT & Local & 5 & Palliative & D & 8 \\
\hline 4 & T4b & S-POCRT & Distant metastases & 24 & CT & D & 28 \\
\hline 5 & T4b & S-POCRT & Distant metastases & 8 & S-PORT & D & 36 \\
\hline 6 & T4a & CT-S-POCRT & Local- regional & 15 & Palliative & D & 26 \\
\hline
\end{tabular}

S: surgery; CT: chemotherapy; PORT: postoperative radiotherapy; POCRT: postoperative chemo-radiotherapy; $D$ : died; AWD: alive without disease.

coma markers (CD99) are uniformly negative. SNUC needs to be distinguished from other primary sinonasal carcinomas because it has a much worse prognosis than other sinonasal tumour. High grade esthesioneuroblastoma, small-cell neuroendocrine carcinoma, solid adenoid cystic carcinoma, sinonasal nasopharyngeal-type undifferentiated carcinoma and malignant melnoma need to be ruled out. Immunohistochemical markers are useful in the differential diagnosis of these histological subtypes sinonasal neoplasm ${ }^{(3)}$. SNUC does not usually show recurrent cytogenetic changes. SNUC is typically negative for EBV. Small cohorts of patients demonstrated overexpression of p16 in the absence of high-risk human papillomavirus (HPV) ${ }^{(9)}$. However, recent studies have shown the presence of HPV DNA ${ }^{(10}$.

Currently, decision making about the treatment of these tumours is based on the experience of several referral institutions and there is no consensus for the standard treatment of SNUC Given the low frequency of these tumours, the treatment of SNUC is challenging and it is difficult to design robust studies to test therapeutic protocols. Furthermore, the optimal order of treatment remains unclear. Despite multimodality therapy ${ }^{2,210-10}$ endorsed universally, the prognosis remains poor and 5-year OS rates range from 20\% to $74 \%$ and the median suvival time is less than 18 months 4.100

Table 4 illustrotes a where patients with SNUC were treated with combined therapy. Studies with at least 15 patients were included to draw consistent conclusions. Yoshida et al. (18) studied the outcomes of 16 patients. The median survival for patients treated by surgery followed by postoperative chemoradiotherapy was $30 \mathrm{r}$ months for patients treated by surgery alone and upfront chemoradiotherapy, respectively. The 2-year locoregional control was $18 \%$ for patients treated with upfront chemoradiotherapy, $37 \%$ for patients treated with surgery alone, and $78 \%$ for patients treated with surgery plus chemoradiotherapy. A 2-year cumulative hazard function pemstrated that the risk of locoregional recurrence after firt year for patients treated with either primary chemofiotherapy or surgery alone $(H R=1.4)$ was greater than four imes the cumulative hazard function for patients treated with surgery plus chemoradiotherapy $(H R=0.3)$. Al-Mamgani et al. (44), utilizing combined-modality treatment, achieved 5-year OS and DFS rates of $74 \%$ and $64 \%$, respectively. This series showed the highest OS and DF but included relatively less $\mathrm{T4}$ tumours and less tumours with orbital and/or intracranial invasion than other studies. They reported an odds ratio of $55(\mathrm{p}=0.003) \mathrm{for}$ patients man indicating an increased risk of local failure when only 2 treatment modalities were used. Patients who underwent surgical resection had significantly better local control than those in whom it was omitted ( 85 vs. $25 \% ; p=0.005$ ). Similar outcomes with the same treatment strategies were reported by other authors ${ }^{2,15,20)}$. These findings suggest that, whenever feasible, gross total resection and post-operative chemoradiotherapy yielded the most favorable outcomes for SNUC. The best sequence of these modalities may be dictated by the performance status of the patient, extent of disease, and available treatment resources. The meta-analyses of 167 patients performed by Reiersen et al. ${ }^{(5)}$ found that patients who had surgery with the addition of radiation and/ or chemotherapy had a $260 \%$ increased chance of survival compared with those who had surgery alone $(\mathrm{OR}=$ $2.6 ; 95 \% \mathrm{Cl}, 0.82-7.87)$. The presence of neck metastases was also a poor prognostic sign.

To our knowledge, our report consists of one of the largest case series to analyse the outcomes after employing combined therapy. In our study, more than $90 \%$ of patients had T4-stage,

Table 4. Literature review*.

\begin{tabular}{|c|c|c|c|c|c|c|c|c|c|c|c|}
\hline & $\begin{array}{c}\begin{array}{c}\text { Gray et } \\
\text { al.1.0) }\end{array} \\
\text { a }\end{array}$ & $\begin{array}{l}\text { Al-Mam- } \\
\text { gani et } \\
\text { al. } 1(1)^{\prime 29}\end{array}$ & $\begin{array}{l}\text { Christo- } \\
\text { pherson } \\
\text { et al.(17) }\end{array}$ & 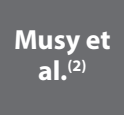 & $\begin{array}{l}\text { Chen et } \\
\text { al.1(15) }\end{array}$ & 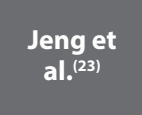 & $\begin{array}{l}\text { Tazler et } \\
\text { al.(10) }\end{array}$ & $\begin{array}{l}\text { Rosenthal } \\
\text { et al. }\end{array}$ & $\begin{array}{l}\text { Mourad } \\
\text { et al. } \text {.20 }^{200}\end{array}$ & $\begin{array}{l}\text { Yoshida } \\
\text { et al.(18) }\end{array}$ & $\begin{array}{c}\text { López et } \\
\text { al.(s) }\end{array}$ \\
\hline $\begin{array}{c}\text { No. } \\
\text { Patients }\end{array}$ & 19 & 21 & 23 & 20 & 21 & 36 & 15 & 16 & 18 & 16 & 17 \\
\hline $\begin{array}{l}\text { Follow up } \\
\text { (months) }\end{array}$ & $\begin{array}{c}25 \\
(2-94)\end{array}$ & $\begin{array}{c}54 \\
(4-163)\end{array}$ & $\begin{array}{c}36 \\
(11-239)\end{array}$ & $\begin{array}{c}31 \\
(4-64)\end{array}$ & $\begin{array}{c}36 \\
(12-70)\end{array}$ & 31 & $\begin{array}{c}30 \\
(11-151)\end{array}$ & $\begin{array}{l}\text { Unspeci- } \\
\text { fied }\end{array}$ & $\begin{array}{c}26 \\
(16-120)\end{array}$ & $\begin{array}{c}14 \\
(1-97)\end{array}$ & $\begin{array}{c}39 \\
(6-96)\end{array}$ \\
\hline $\begin{array}{c}\text { Surgery- } \\
\text { based } \\
\text { treatment }\end{array}$ & $63 \%$ & $67 \%$ & $65 \%$ & $55 \%$ & $90 \%$ & $47 \%$ & $66 \%$ & $93 \%$ & $83 \%$ & $63 \%$ & $82 \%$ \\
\hline $\begin{array}{l}\text { Chemo- } \\
\text { therapy }\end{array}$ & $100 \%$ & $76 \%$ & $70 \%$ & $71 \%$ & $62 \%$ & $25 \%$ & $47 \%$ & $63 \%$ & $83 \%$ & $63 \%$ & $100 \%$ \\
\hline $\begin{array}{l}\text { Radio- } \\
\text { therapy }\end{array}$ & $100 \%$ & $100 \%$ & $100 \%$ & $95 \%$ & $100 \%$ & $64 \%$ & $93 \%$ & $100 \%$ & $83 \%$ & $63 \%$ & $100 \%$ \\
\hline $\begin{array}{l}5 \text { years - } \\
\text { LCR }\end{array}$ & & $80 \%$ & $75 \%$ & $\begin{array}{l}\text { Unspeci- } \\
\text { fied }\end{array}$ & $59 \%$ & $\begin{array}{l}\text { Unspeci- } \\
\text { fied }\end{array}$ & $\begin{array}{c}78 \% \\
3 \text { years }\end{array}$ & $79 \%$ & $\begin{array}{c}72 \% \\
3 \text { years }\end{array}$ & $78 \% *$ & $\begin{array}{c}76 \% \\
3 \text { years }\end{array}$ \\
\hline $\begin{array}{l}5 \text { years } \\
- \text { - os }\end{array}$ & $45 \%$ & $74 \%$ & $32 \%$ & $\begin{array}{c}47 \% \\
2 \text { years }\end{array}$ & $43 \%$ & $\begin{array}{l}10 \text { months } \\
\text { median } \\
\text { survival }\end{array}$ & $\begin{array}{c}67 \% \\
3 \text { years }\end{array}$ & $63 \%$ & $\begin{array}{c}50 \% \\
3 \text { years }\end{array}$ & $75 \% 0^{*}$ & $58 \%$ \\
\hline $\begin{array}{l}\text { 5- years - } \\
\text { DFS }\end{array}$ & $51 \%$ & $64 \%$ & $42 \%$ & $\begin{array}{l}\text { Unspeci- } \\
\text { fied }\end{array}$ & $64 \%$ & $\begin{array}{l}\text { Unspeci- } \\
\text { fied }\end{array}$ & $\begin{array}{c}77 \% \\
3 \text { years }\end{array}$ & $\begin{array}{l}\text { Unspeci- } \\
\text { fied }\end{array}$ & $\begin{array}{c}65 \% \\
3 \text { years }\end{array}$ & $\begin{array}{l}\text { Unspeci- } \\
\text { fied }\end{array}$ & $61 \%$ \\
\hline
\end{tabular}

LC: local control rate; OS: overall survival; DFS: disease free survival, § Present series.

${ }^{*}$ Only the series reported by Al -Mamgani ${ }^{(1)}$ and Yoshida ${ }^{(18)}$ showed a statistical difference in survival between the treatment groups favoring surgical-based treatment.

and $12 \%$ of patients have a node-positive disease at diagnosis as in most series ${ }^{\left({ }^{14}\right)}$. Four distinct therapeutic regimens were employed but every patient in our cohort received RT (to the primary tumour and ENI). Fourteen patients (82\%) underwent surgical extirpation of the tumour via craniofacial resection. Of these patients, 5 were operated through an endoscopic approach. So far, only one previous series showed cases in which this approach was used, with success ${ }^{211)}$ Choosing an endoscopic approach does not mean that a radical resection cannot be performed. One of these patients developed a distant metastasis and another developed local recurrence, but she presented initially with a very advanced tumour involving the brain. Endoscopic surgery reduces the number of complications and morbidity due to surgery and it reduces possible complications due to RT after upfront open surgery. Moreover, due to the fact that resection of SNUC with wide margins is not always possible either by open or endoscopic techniques, because it would affect cranial nerves, the eyes, internal carotid arteris or the brain endoscopic surgery in SNUC could be offered in most patients
(22). The mainstay treatment used at our institution is craniofacia resection plus chemoradiotherapy (10 patients). In cases which respectability upfront is questionable, induction chemotherapy was considered to reduce the tumour size and therefore facilitates surgery. However, these cases carry a dismal prognosis. Despite aggressive multimodality management, calculated 5-year OS and DFS rates were $58 \%$ and $61 \%$, respectively, simila to 5 -year OS described in the literature (20-63\%) al. ${ }^{5}$ in a meta-analysis found a DFs rate of $26,3 \%$. The 3-year local control rate was $76 \%$, being $100 \%$ in the chemoradiotherapy group and $71 \%$ in surgery-based group. Similar results using definitive chemoradiation have been described by some authors (10.17), although differences were not significant. Sometimes non surgery-based treatment can lead to prolonged survival for patients with advanced disease. The inclusion in the surgical group of 3 patients with very advanced tumours, and the small number of patients will have limited this analysis SNUC is reputed to be refractory to even the most radical therapy and to carry a poor prognosis, particularly when the tumour transgresses the 
cranial base or the orbit. However, in our series the presence of dural or orbital invasion, were not correlated with poor local control. Obviously lymph node and distant metastases carry a worse prognosis ${ }^{(5,17)}$. Elective neck irradiation seems mandatory in SNUC.

Up-front chemoradiotherapy was used in selected cases to minimize the complications of radical of surgical treatments. It is noteworthy that Musy et al. (2) $^{(2)}$ found residual tumour in $70 \%$ of surgical specimens after primary chemoradiation. This suggests that resection should be considered as a essential part of therapy. Indeed all survivors in the largest study of SNUC were treated with sugry as pat of their management ${ }^{123}$. Morever, gross total with subtotal resection ${ }^{(15)}$.

The use of chemotherapy in the treatment of SNUC is controvesial and needs to be further explored. Adjuvant chemotherapy is sometimes used in an attempt to down-staging the tumour before surgical resection. Chemotherapy does not appear to improve the outcome in these patients because they likely have more advanced disease. Rischin et al (13) suggested reducing the incidence of distant metastases using induction chemotherapy. In our series, all patients who developed distant metastases were treated without induction chemotherapy and those who received chemotherapy, had very advanced tumours and died of locoregional disease.

An irradiation dose-response relationship might exist in cas of SNUC ${ }^{(24)}$. Doses greater than 60 Gy seem to be more favourable in local control rates (14) New radiation techniques as intensity-modulated RT (IMRT), volumetric-modulated arc therapy (VMAT), tomotherapy and proton therapy enable the achievement of sharp dose gradients near the targeted volumes (25). The greater conformality afforded by these new technique produces a lower rate of radiation-induced toxicity and increases therapeutic efficiency. With IMRT and VMAT, microscopic tumour spread cannot only be pursued around the primary site and through the lymphatic channels to the neck nodes, but also to other routes of dissemination. IMRT compared to 3DCRT, improved DFS and local control and decreased acute and late toxicity ${ }^{(1426)}$. We used IMRT with concurrent chemotherapy in only 3 patients after surgery. All of them are alive without disease and without treatment-related complications. A patien who developed cervical and distant metastasis was treated with VMAT and remains without disease. Other authors have employed proton beam radiation with high efficiency and low toxicity 10,1 , Precision RT could be an important conpo the treatment of these tumours, both the primary disease and the recurrence.

As is shown in the current study, local recurrence and distant metastases remain significant problems in patients with SNUC Highly conformal RT techniques and intensification of chemotherapeutic schedules should be implemented in the expectation of improving the outcomes (14). Moreover, to understand the biological characteristics of SNUC and to develop novel alternative treatments, it is essential to establish a reliable and phenotypically accurate tumour model system for SNUC. However, attempts to understand the genetics and biology of SNUC and to identify mol

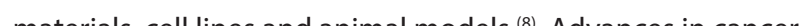
materils, cell mes and an treatment, including the introduction of molecular targeted the rapies (e.g. c-KIT overexpression without activating mutation) ${ }^{27}$ may yield significant improvements in the prognosis of patients with SNUC. Polymorphisms were noted within the promoter region of VEGF, which may merit future studies as predictive biomarkers for treatment response or overall survival ${ }^{28}$. Recently, Takahashi et al. (29) reported the establishment and characterization of two novel SNUC cell Ines that are highly tumourogenic and maintain in the histological and molecular features of the original tumour. These cell lines may serve as useful tools for the future study of SNUC and in the development and testing of novel therapies for this deadly disease.

\section{Conclusion}

Management and outcomes of SNUC have improved due to dvances in surgery and RT. Gross tumour resection and postpostSWUC. Because of te inpovent in the SNUC. Because of the mprovement in therapeutic ratio, highly conformal RT techniques, such as IMRT, should be implemened. In patients where the surgical resection is unattainable, an attempt of down-staging by induction chemotherapy might be considered. Endoscopic surgery is suitable following the principles of oncological surgery with adequate exposure and margins. ENI would be advocated in all patients with locally dvanced disease.

\section{Authorship contribution}

All authors have made substantial contributions to the concep tion, the writing and editing of the manuscript.

\section{Conflicts of Interest}

None of the authors have financial interests in companies or other entities that have an interest in the information in the contribution. tumours. Lyon: IARC, 2005; 19.

Musy PY, Reibel JF, Levine PA. Sinonasa
undifferentiated carcinoma: the seara for better outcome Laryngoscope. 2002: 112 $1450-1455$.

3. Franchi A, Palomba A, Cardesa A. Current diagnostic strategies for undifferentiated sinuses. Histopasthology 2011: 50: 1034sinus
1045.

4. Reiersen DA, Pahilan ME, Devaiah AK. Metaanalysis of treatment outcomes for sinona sal undifferentiated carcinoma. Otolaryngol Levine PA Frierson HE tr, Stewart EM Mill SE, Fechner RE, Cantrell RW. Sinonasal undifferentiated carcinoma: a distinctive an highly aggressive neoplasm. Laryngoscope. 6. Enepekides DJ. Si ated carcinoma: an update. Curr Op 225. Moreno $C$, Lut resection. Indications and technical aspecis. Acta Otorrinolaringol Esp. 2012: 63:413-42.

8. Bell D, Hanna EY. Sinonasal undifferentiated carcinoma: morphological heterogenetyy, diagnosis, management and biologicad 13:285-296.

Wadsworth B, Bumpous JM, Mart AW, Nowacki MR, Jenson AB, Farghaly H. Expression of pl6 in sinonasal undifferentthed carcinoma (SNUC) without associated Pathol. 2011; 5: 349-354

10. Gray ST, Herr MW, Sethi RK, et al. Treatment outcomes and prognostic factors including uman papillomavirus ( $\mathrm{HPV}$ ) for sinona (15) (n) M. Sinonasal undifferentiated carcinoma case series and review of the literature. Neurosurgery.2000, $47.750-755$.

Sinonasal undifferentiated carcinoma: et 3-year experience at a single institution. Skull Base. 2010r; 20: 61-67.

Corly D, Porcedal S, Peters L Martin chemoradiation in patients with sinonasal undifferentiate
2004; $26: 435-441$. 4. Al-Mamgani A, van Rooij P, Mehilal R, Tans
L, Levendag PC. Combined-modality treatment improved outcome in sinonasal undifferentiated carcinoma: single-instituof the literature Eur Arch Otorhind Tryngo 2013; 270: 293-299

5. Chen AM, Daly ME, El-Sayed I, et al. aatterns of failure after combined-modality approaches incorporating radiotherapy for had and neck Int Rad Oncol Biol Phys. 2008; 70: 338-343.

6. Tanzler ED, Morris CG, Orlando CA, Werning , Mendenhall WM. Management of snonasal undifferentiated carcinoma. He

Morris $\mathrm{CG}$, Mendenhall WM. Radiotherapy for sinonasal undifferentiated carcinoma Am J Otolaryngol. 2014; 35 : 141-146.
18. Yoshida E, Aouad R, Fragoso R, et al. Iosthida E, Aouad R, Fragoso R, et modality therapy for sinonasal undifferentiated carcinoma of the head and neck. Am Otolaryngol. 2013; 34: 658-663.

Rosenthal D, Barker J, El-Naggar A, et Sinonasal malignancies with neuroendo-
crine differentiation: patterns of failure according to histologic phenotype. Cancer. Fouad Mourad W, Ha

RA, et al Timodity nestock D, Shourba asal undifferentited cacinoma and reve 584-588.

Revenaugh PC, Seth R, Pavlovich JB, Kno D, Batra PS. Minimally invasive endoscopic inoma. Am J Otolaryngol. 2011: 32: 464469. Lund VJ, Stammberger $H$, Nicolai Castelnuovo P, et al. on behalf of European
Rhinologic Society Advisory Board on Rhinologic Society Advisory Board on of Nose, Paranasal Sinus and Skull Bas Tumours. European position paper on the nose, paranasal sinuses and skull base
Rhinol Suppl. 2010: 22: 1-143.
23. Jeng $Y M$, Sung $M T$, Fang $C L$, et al. Sinonasa undifferentiated carcinoma and nasoma: two clinically biologically, and histopathologically distinct entities. Am I Surg Pathol. 2002; 26: 371-376.

. Gorelick J, Ross D, Marentette L, Blaiv case series and review of the literature. Neurosurgery. 2000: 47: 750-755.

25. Spratt D, Cabanillas R, Lee NY. The paranasa smuses en target volume delineation and ume delineation and field setup. A arget vol guide for conformal and intensity-mod Ited radiation therapy. Berlin- Heidelberg Springer, 2013; 45-49.

DinX, Vanstraelen B, J Jorissen M, Vander Poorten V, Nuyts S. Intensity-modulated outcome compared to conventional radiotherapy. Int J Radiat Oncol Biol Phys. 2010 78: 998-1004.

Chernock RD, Perry A, Pfeifer JD, Holden . evaluation for EGFR, C-KIT, and HER2/neexpression. Head Neck. 2009; 31: 919-927. 28. Gelbard A, Hale KS, Takahashi Y, et al. Molecular profiling of sinonasal undiffer15-21. 9. Takahashi $Y$, Kupferman ME, Bell $D$, et a
Establishment and characterization of nove cell lines from sinonasal undiferentiated 6187

\section{Fernando López Álvarez} C/Marcos Peña Royo $20-4{ }^{\circ} \mathrm{A}$

Tel: +34-985-253 607

E-mail: flopez_1981@yahoo.es

\section{References

